\title{
Are pre-service Primary School teachers prepared to teach science by inquiry?
}

\section{Montero-Pau, Javier ${ }^{a}$; Tierno, Sandra Pilar ${ }^{b}$ and Tuzón, Paula ${ }^{a}$}

${ }^{a}$ Departamento de Didácticas de las Ciencias Experimentales y Sociales, Facultad de Magisterio, Universitat de València, Spain. ${ }^{\text {b}}$ Facultad de Enfermería, Universidad Católica de Valencia “San Vicente Mártir”, Spain.

\begin{abstract}
Inquiry-based science education (IBSE) focuses on the development of science process skills. This teaching methodology has been shown to be especially effective during Primary School as it allows children to explore and confront their own ideas about Nature. Also, a methodology based on process skills is coherent with the main purpose of this educational stage where children need to learn to do things. In order to implement a methodology based on science process skills Primary teachers need to know to use science process skills, and how to teach them. In this paper we address whether Spanish pre-service teachers are able to implement IBSE. We focus on pre-service Primary School teachers and compare our results with inservice teachers and a random sample of non-teachers. We explore their level of knowledge about science process skills and if pre-service teachers know how to develop an inquiry-based learning sequence. An overview of the situation of science education and teaching of scientific skills among the degrees on Primary Education in Spain is also presented. Our results show that pre-service teachers have a lack of knowledge on science process skills and fail when they attempting to build a learning sequence based on inquiry.
\end{abstract}

Keywords: Inquiry-based science; university education; science process skills. 


\section{Introduction}

The teaching of science by inquiry (IBSE: Inquiry-based science education) incorporates the science process skills as part of the learning process (Harlen \& Qualter, 2009; Minner et al., 2010). Students, besides learning science concepts, learn to make observations and hypothesis, to build experiments and fair tests, to identify the different variables that affect a phenomenon, to measure, to extract conclusions from data, etc. Including scientific skills in the learning process is coherent with the nature of science, and it is specially recommended in Primary School for two reasons (Harlen \& Qualter, 2009): first, children are allowed to test their own ideas about Nature. Children's ideas are sometimes misaligned with the scientific ideas, as they tend to be strongly biased by their sensory experience. An educational strategy like IBSE provides opportunities to confront their experience with evidence, which is key to overcome science misconceptions and develop a critical thinking. Second, children need to learn through action, they need hands-on activities to understand. Also, a methodology based on process skills is coherent with the main purpose of this educational stage where children need to learn to do things.

To implement a methodology based on science process skills teachers should know, first, science process skills, and second, how to teach them. This two-step level on inquiry-based science teaching is not easy to achieve and requires University programmes properly focused for that; even more if the level of pre-service teachers' science education is low when they start the degree (Crawford, 1999). There are studies stressing the fact that very few teachers (among the most motivated) teach science by inquiry or relate contents to the nature of science (Capps \& Crawford, 2013). Actually, many teachers think they do it when in fact they do not (Capps \& Crawford, 2013; Oppong-Nuako et al., 2015). This shows confusion at a pedagogical level, coming in part from teachers' education at University. Programmes seem to be far to provide a proper education for teachers on inquiry. This has been barely investigated in Spain (Cañal de León et al., 2013; García-Carmona et al., 2016) and it is important to do research on both steps: What is the level of knowledge of teachers about science process skills? Do teachers know how to teach them? In this study we aim to investigate on those questions focusing on pre-service Primary School teachers' education.

In this work, we analyze what is the level of knowledge of pre-service teachers about science process skills from middle courses at University. We compare the results with inservice teachers and a random sample of non-teachers. On the other hand, we analyze how is the structure of teaching sequences proposed by pre-service teachers that already took a course on science teaching. Finally, we give a general overview of Spanish Teachers' Education Faculties about inquiry. The goal is, first, to evaluate whether pre-service teachers have a good level of knowledge of science process skills and, second, wheter they know how to build a teaching science by inquiry or whether the teaching sequences contain any inquiry skills in their educational context. 


\section{Methodology}

There are several tests that measure the level of knowledge of science process skills (Monde-Monica, 2005; Miles, 2010; Shahali et al., 2015), both for teachers and students, and from primary and secondary school. The Test of integrated process skills (TIPS and TIPS II) (Burns et al., 1985; Dillashaw \& Okey, 1980) has been validated and used in many studies for that purpose. In this study we used the TIPS II test (Burns et al., 1985) that is a multichoice questionnaire that measures five science process skills: (a) making operational definitions based on a description of an investigation (6 questions), (b) identify the manipulated, responding and controlled variables (12 questions), (c) state hypothesis based on a description of variables involved in an investigation (9 questions), (d) interpret data and graphs (6 questions), and (e) given a hypothesis, design an investigation to test it (3 questions). The test was administered to a convenience group of 110 pre-service Primary teachers of $2^{\text {nd }}$ and $3^{\text {rd }}$ course (out of 4 ) at the Teachers' Education Faculty at University of Valencia. All of them had attended a course on general science contents, but they had not attended any course on science teaching yet. Age, gender and secondary school itinerary (sciences, social sciences, humanities/arts or technical studies) were also registered. Additionally the test was administered to a convenience group of 16 in-service teachers, and to a random sample of 26 of non-teachers. In the case of the random sample, the higher education degree they hold was also registered as well as a self-assessment about their science knowledge (0 to 10 scale).

We have also analyzed nine teaching sequences proposed by 43 students in groups of $4 / 5$ people that already took a course on science teaching in the same Faculty. They were asked to build a teaching sequence using the IBSE approach about a concept related to the topic The fruit and the seed. They had 45 minutes to do it. To evaluate the teaching sequences we assessed whether the set of activities work on the following items with children: (1) observation, (2) making hypothesis and predictions, (3) designing an experiment, (4) building conclusions from data and (5) whether the set of activities involving process skills drives to conclusions about a particular concept. For each item, a set of minimum requirements was defined: (1) Classification and grouping of features. Sharing observations in small groups and/or the whole class. Categorization and prioritization of observations. (2) Providing opportunities and time for children to think how different observations are related, and suggesting hypothesis to explain them. Choosing one or some hypothesis (statements) to analyse. (3) Planning a detailed research (e.g. what and how to measure, what materials and instruments are needed, what to do step by step). Identifying the variables that should be varied and controlled. Planning a fair test. (4) Showing and interpreting data according to the proposed hypothesis. Analysing the limitations of the experiment. (5) Does the observation scenario show the variables that children need to detect to build hypothesis? Do the set activities drive children to propose proper 
experiments related to the phenomenon? Is the concept (or set of concepts) clear at the end of activities?

Finally, we looked at the programmes of 21 Teachers' Education Faculties in Spain to see the distribution of subjects and hours per subject related to general science and science teaching courses. Besides, we looked for some keywords related to inquiry on the 83 teaching guides of those subjects: "inquiry", "observation", "hypothesis", "identify variables", "interpret data", "graph", "design investigations" and "design experiments". We checked the context where they were found in cases of doubt.

\section{Results and discussion}

The age of participants varied from 19 to 21 years old in pre-service teacher, to 41.4 (19 to $67)$ years old on average in the non-teachers sample. In-service teachers have on average 31.9 (24 to 58) years old and 16.25 (1 to 35) years of teaching experience. Gender distribution varied from $80 \%$ women in pre-service teachers, $93 \%$ in in-service teachers and $39 \%$ in the non-teacher sample. $87 \%$ of pre-service teacher come from a non-science itinerary in secondary school. $43 \%$ of non-teachers sample have had a science-oriented education, $85 \%$ hold a university degree and on average their feel that their scientific knowledge is of 5.7 out of 10 .

\subsection{Level of knowledge on science process skills}

The average frequency of correct answers in pre-service teachers is $0.64 \pm 0.13$ (mean \pm standard deviation), almost like in-service teachers $0.66 \pm 0.17$ and lower than in the nonteacher group $0.75 \pm 0.11$. These differences are statistically significant between pre/inservice teachers and non-teachers (Student's t-test p-value<0.001). In the non-teachers group, average frequency of correct answers is higher either if they have had a scienceoriented education $(0.78)$ or not $(0.73)$ and is not correlated with their self-perception of their level of science knowledge. Test failure rate (i.e., frequency of correct answers lower than 0.5 ) is very low. Only $14 \%$ of pre-service teachers fail, more or less the same as inservice teachers $(19 \%)$ whereas nobody in the non-teacher group fails. However, high scores rates are very low too. Only $2 \%$ of pre-service teachers have correct answers' frequencies higher than 0.85 ( $6 \%$ for in-service teachers and $22 \%$ for non-teachers).

There are no differences between pre-service teachers' scores depending on their secondary school itinerary (ANOVA p-value=0.162). Students coming from sciences do not score significantly better than the others. However, there are significant differences between preservice teachers' scores depending on the course (Student's t-test p-value<0.001). The average frequency of correct answers in students from the $2^{\text {nd }}$ course is $0.57 \pm 0.12$, while for the students from the $3^{\text {rd }}$ course is $0.69 \pm 0.11$. These differences could be due to the fact that students in $3^{\text {rd }}$ course are grouped based on their grades, whereas in $2^{\text {nd }}$ course they are not 
sorted. In our sample, the participating students of $3^{\text {rd }}$ course likely came from groups with higher grades. In any case, differences between pre-service teachers, and in-service and non-teachers samples hold either when grouping all pre-service teachers together or when they are split by course.

Results are different for the five different groups of questions addressing different science skills. Pre-service and in-service teachers score worse than non-teachers in all groups of questions, but these differences are only statistically significant in questions related to identify types of variables (group 1), make operational definitions (group 2) and state hypothesis (group 3). In group 2 of questions, pre-service teachers score significantly worse than the other two samples, while in groups 1 and 3 both pre-service and in-service teachers score significantly worse than non-teachers. The group of questions with the lowest score is that related to identify variables (group 1). Particularly, those questions addressed to the identification of manipulated and controlled variables (only $25 \%$ or less give the correct answer). Regarding to the formulation of hypothesis (group 3), pre-service teachers are able to identify the hypothesis when a detailed investigation is provided, however they get worse results when a more open description of an investigation is provided. The same trend is found in in-service and non-teachers groups.

In general, pre-service teachers' answers show low correlation within group of questions (Cramer's $\mathrm{V}<0.5$ in all groups). The lowest correlation is found in group 3 (Cramer's $\mathrm{V}=0.15$ ), probably due to the different ways of asking about hypothesis building (commented above). Results are very similar when in-service teachers and non-teachers are included in the sample.

\subsection{Level of inquiry in science teaching sequences}

Nine teaching sequences about a concept related to the topic The fruit and the seeds were prepared by 43 students working in groups of $4 / 5$ people. Students were asked to use an inquiry-based approach, however the level of inquiry in all those sequences is very low. None of the sequences presents anything related to designing experiments (items 3) nor building conclusions from any data (item 4). Activities do not show a clear concept to be investigated, and there are not a series of steps to guide children through the investigation (item 5). In some of them, observation (item 1) is worked, but the level of training of this process skill (classification, association, hierarchical organization of the observed items, etc.) is very low. In all cases, there is only a general wording saying something like "observe this and tell me what you see". There are no guidelines to make the observations, the scenario is not specified and the purpose is not clear. There are three cases where the observation is done after an explanation of the concept that is (presumably) being investigated: "After explaining what are the parts of a fruit and their functions, we ask the children to identify them on some real fruits". So, the main purpose of the observation 
process skill (distinguish features to build hypothesis from them) is lost. There is only one case where they work partially on building hypothesis, although without a proper previous observation scenario, so the activity is too rough. Besides, it ends up saying "the teacher guides the debate to the true hypothesis by reasoning with children", blocking any investigation from there. The general structure of the teaching sequences consists in a first part of making questions to children or proposing a general observation and then explaining the concept. There are only two cases where they propose to do "an experiment" after the first part. But this experiment is completely demonstrative (just to check the previous explanation) and is not a part of an investigation. There are two other cases where, after a first part, they say "and now we would do an investigation by working in the school's vegetable garden" or "and now we would do a research project about this", but they do not specify how.

It is surprising the level of incoherence among the activities of the same sequence according to a proper IBSE approach. Students to not seem to know the general structure of teaching sequences based on inquiry nor how to work on process skills and concepts at the same time. It is also striking the lack of theoretical background. Most of the teaching sequences contain misconceptions, error or teleological arguments like "fruits provide us vitamins and that is why they are edible. That is one of their functions". This shows a clear problem of resources in the process of building teaching sequences.

\subsection{Science education and inquiry on Primary Teacher degrees}

The curriculum of Primary Teacher degree in Spanish Education Faculties typically includes between two and four mandatory subjects related to science education. Most of these subjects $(68.5 \%)$ take 60 hours. Three kinds of subjects can be found: general courses on basic contents of science (C), courses on didactics of science (T), and courses that combine both, that is general science contents and didactics of science (CT). C subjects tend to be taught in the first years (1st and 2nd year), only science subjects covering specialized contents are taught in the last years (3rd and 4th). T subjects are mainly taught in the last years (3rd and 4th), and CT subjects in the middle years (2nd and 3rd). The search of inquiry-related keywords on 83 teaching guides corresponding to mandatory and non-mandatory subjects shows that the rate of appearance of inquiry terms is very low. "Observation" is the keyword with a higher rate of appearance, it appears in $26.5 \%$ of the guides with a frequency of 0.26 times per guide. "Interpret data", "inquiry" and "hypothesis" appear $0.18,0.12$ and 0.10 times per guide respectively. The rest of the keywords are either absent or only appear one time. Globally, our results show that the presence of inquiry at University science teaching programmes is very scarce. 


\section{Conclusions}

Teaching science by inquiry in Primary School is one of the big challenges in science education since many years ago. There are countries (USA, France, UK, Finland, etc.) that have already implemented these programmes with some successes and limitations. One of the main obstacles is the education of pre-service teachers. Students of Primary Teacher degrees require to train their science process skills, and learn how to teach them to children. In Spain, the introduction of inquiry-based science in Primary Schools is either rare or incipient. Our results show that education of pre-service teachers is not promising to reverse this situation. Presence of inquiry and inquiry skills in subjects covering science contents and didactics of science in the Primary Teacher degrees in Spain is very limited. Despite having low failing rates in the TIPSII, pre/in-service teachers score lower than nonteachers. Pre-service teachers fail in questions deeply related to science process skills that are not typically covered in other subjects, like maths. They fail on identifying variables when building an experiment, on making hypothesis and finding operational definitions. Primary teacher students also fail on doing teaching sequences by inquiry. Only observation is worked in some cases. Activities do not follow the logical development of a research, and the goal of the sequence is not clear. Overall, our results show the need to strengthen the training in science process skills of future Primary teachers. This situation inevitably involves reinforcing and improving curricula of science subject of Primary Teacher degrees.

\section{References}

Burns, J. C., Okey, J. R., \& Wise, K. C. (1985). Development of an integrated process skill test: TIPS II. Journal of Research in Science Teaching, 22, 169-177.

Cañal de León, P., Criado, A. M., García Carmona, A., \& Muñoz Franco, G. (2013). La enseñanza relativa al medio en las aulas españolas de educación infantil y primaria: concepciones didácticas y práctica docente. Investigación En La Escuela, 81, 21-42.

Capps, D. K., \& Crawford, B. A. (2013). Inquiry-Based Instruction and Teaching About Nature of Science: Are They Happening? Journal of Science Teacher Education, 24, 497-526.

Crawford, B. A. (1999). Is It Realistic to Expect a Preservice Teacher to Create an Inquirybased Classroom? Journal of Science Teacher Education, 10, 175-194.

Dillashaw, F. G., \& Okey, J. R. (1980). Test of the integrated science process skills for secondary science students. Science Education, 64, 601-608.

García-Carmona, A., Criado, A. M., \& Cruz-Guzmán, M. (2016). Primary pre-service teachers' skills in planning a guided scientific inquiry. Research in Science Education, $1-22$.

Harlen, W., \& Qualter, A. (2009). The Teaching of Science in Primary Schools. Oxon: David Fulton. 
Miles, E. (2010). In-Service Elementary Teachers' Familiarity, Interest, Conceptual Knowledge, and Performance on Science Process Skills. Theses. Illinois, USA: Southern Illinois University at Carbondale.

Minner, D. D., Levy, A. J., \& Century, J. (2010). Inquiry-based science instruction-what is it and does it matter? Results from a research synthesis years 1984 to 2002. Journal of Research in Science Teaching, 47, 474-496.

Monde-Monica, K. M. (2005). Development and validation of a test of integrated science process skills for the further education and training learners. Master's thesis. Hatfield, South Africa: University of Pretoria.

Oppong-Nuako, J., Shore, B. M., Saunders-Stewart, K. S., \& Gyles, P. D. T. (2015). Using Brief Teacher Interviews to Assess the Extent of Inquiry in Classrooms. Journal of Advanced Academics, 26, 197-226.

Shahali, E. H. M., Halim, L., Treagust, D. F., Won, M., \& Chandrasegaran, A. L. (2015). Primary School Teachers' Understanding of Science Process Skills in Relation to Their Teaching Qualifications and Teaching Experience. Research in Science Education, 125.

Verdugo-Perona, J. J., Solaz-Portolés, J.-J., \& Sanjosé-López, V. (2016). Pre-service Primary Teachers' Scientific Knowledge and Attitudes towards Science Learning and Their Influence on Understanding of the Nature of Science. Croatian Journal of Education, 18. 